\title{
Evolution of interdisciplinary collaboration: what are stimulating conditions?
}

\author{
Jurian Edelenbos ${ }^{1 *}$, Nanny Bressers ${ }^{1}$ and Lieselot Vandenbussche ${ }^{1}$ \\ ${ }^{1}$ Department of Public Administration and Sociology, Erasmus University Rotterdam, PO Box 1738, \\ 3000 DR Rotterdam, The Netherlands; Emails: bressers@fsw.eur.nl and Vandenbussche@fsw.eur. \\ $\mathrm{nl}$ \\ *Corresponding author. Email: edelenbos@fsw.eur.nl
}




\section{ABSTRACT}

In the past, the attention paid to interdisciplinary working focused on putting it into practice. As it turns out, this is not without problems. This paper looks closely at the development of interdisciplinary working in a longitudinal case study. Our objective is to provide insight into the evolution of interdisciplinary working in practice. We discuss a European project, known as BRAINPOoL, and deal with knowledge integration, common ground, reflexivity, bridging internal interaction, and project commitment as core aspects of interdisciplinary research. We found that these factors evolved in the case study and we also found important evolutionary conditions: facilitative leadership, professional differences, and willingness to learn and cooperate are important drivers of interdisciplinary research.

Keywords: interdisciplinary; evolution; knowledge; commitment; facilitative leadership; integration 


\section{INTRODUCTION}

Complex social issues need interdisciplinary working as these issues transcend social, ecological, economic, and environmental aspects (Petts et al., 2008; Haapasaari et al., 2012). This is a matter not only recognized by science, but also in (policy) practice, for instance at the European Union. Over the past years the attention to interdisciplinary working is focused at getting this into practice, as it turns out that this is not without problems (Huutoniemi et al., 2010; Klein, 2008; Bruce et al., 2004).

Much literature devotes attention to conceptual clarification and theoretical underpinnings of interdisciplinary working (c.f Klein, 2008). And although more empirical material is getting available on conditions and challenges for the implementation of interdisciplinary working (c.f. Petts et al., 2008; Huutoniemi et al., 2010), there is still not much longitudinal in-depth case analysis present, although some exceptions are present (Barnes et al, 2002;Guimera et al, 2005; Podesta et al, 2013; Haapasaari et al., 2012; Huutoniemi, 2010). Interdisciplinary working however "...could be considered as a process, an evolution, rather than a state, thereby requiring that - if its characteristics are to be captured - they should portray development over time" (Wagner et al, 2011: 23). Longitudinal case-analysis and monitoring can give more insight in the way interdisciplinary work(ing) evolves over time, i.e. in the process of interdisciplinary work, and which up and downs interdisciplinary work processes face in practice.

We therefore formulate the following research question in guiding our research and article: how does interdisciplinary working evolve through time in a real-life project and which factors shaped this evolution? We conduct a longitudinal in-depth case study analysis to answer this research question. Our case concerns the EU FP7-funded project BRAINPOoL, which worked on bringing alternative indicators for welfare measurement ('Beyond-GDP') into policy. BRAINPOoL ran from October 2011 until April 2014, and the consortium founded for this project consisted of seven organizations from five European countries. The majority of these organizations had much experience with the Beyond-GDP field, whereas it was a relatively new topic for some others. Organizations included four universities, an independent research organization, and two think tanks. We have been involved in this project as internal evaluators, and have therefore been able to conduct a longitudinal analysis of interdisciplinary working in this case.

The structure of the article is as follows. First, we conceptualize interdisciplinary research (section 2). We define five elements that we see as the core building blocks of interdisciplinary working. Then, second, we use these five elements in our section on methodology and operationalization to introduce our assessment approach of interdisciplinary working in BRAINPOoL (section 3). The subsequent

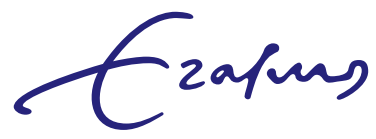


section discusses the case and the results on the five elements, based on our longitudinal multi-method research (section 4). In the discussion section we deduce stimulating and hampering factors for interdisciplinary working from the analysis (section 5). We end our paper with drawing conclusions and lessons (section 6).

\section{CONCEPTUALIZING INTERDISCIPLINARY RESEARCH}

\subsection{Positioning interdisciplinary research}

Generally, a threefold division is made: multidisciplinary working, interdisciplinary working, and transdisciplinary working (Bruce et al. 2004: 459). The latter concept, transdisciplinary research, is used for research in which not only different scientific disciplines are involved but also a wide range of stakeholders in society (citizens, community organizations, NGOs, private companies, etc.) are engaged (Klein, 2008). In this way also non-academic forms of knowledge (so-called local knowledge sources, Edelenbos et al, 2011) are included.

Multidisciplinary research is a conglomeration of distinct disciplinary components, whereas interdisciplinary research refers to a more synthetic attempt of mutual interaction (Huutoniemi et al., 2010; Aboelela et al, 2007; Klein, 2008). In the first, "...the implication is a division of labour in which different disciplinary frames survey separate aspects of the same whole. There is cooperation between disciplines, but the methodological processes of disciplinary-based investigation remains distinct" (Horlick-Jones and Sime, 2004: 444; Huzair et al, 2013; Petts et al, 2008).

Interdisciplinary research then is based on active interaction across (scientific) disciplines. "This interaction takes place not only in the framing of research problems and coordinating knowledge flows between fields, but also in the execution of research and the formulation and analysis of results" (Huutoniemi et al., 2010: 83). In this kind of research, separate bodies of specialized data, methods, tools, concepts, or theories are often integrated in order to create a synthetic view or common understanding of a complex issue or problem: it goes beyond a simple sum of the parts (ibid). There is synthesis or translation of knowledge, frames and understanding among the participants (Huzair et al, 2013; O’Brien et al, 2013). In contrast to multidisciplinary research, interdisciplinary research challenges the structure or functioning of academic communities and requires mutual adaptation and learning in the academic worldviews of the researchers themselves (Bruce et al., 2004; Lyall et al, 2013). Klein (2008: 117) defines interdisciplinary research as "a process in which members of different fields work together over extended periods to develop novel conceptual and methodological frameworks with the potential to produce transcendent theoretical approaches".

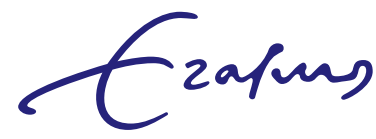


In literature reviews on the topic, different aspects further defining and refining the idea of interdisciplinary work and research (Aboelela et al, 2007; Klein, 2008; Huutoniemi et al, 2010; Klein, 2010). However, many of these aspects overlap and recur throughout literature. We found five recurring aspects of interdisciplinary research that form the basis of our working definition for this paper. These aspects are: (1) integration of separate bodies of knowledge (Huutoniemi et al., 2010; Klein, 2008; Bruce et al., 2004; Holbrook, 2913); (2) the development of common ground among different researchers (Huutoniemi et al. 2010 Huzair et al, 2013); (3) reflexivity and mutual adaptation (Bruce et al. 2004; Lyall et al, 2013); (4) crossing boundaries and bridging interactions between organizations and/or disciplines (Bruce et al., 2004; Klein, 2008); and (5) the personal and team commitment to interdisciplinary effort (Gray, 2008; Klein, 2008). Based on these five aspects we define interdisciplinary research as " $a$ way of working among researchers with different disciplinary backgrounds aimed at developing a synthesis view on a given topic through knowledge integration processes consisting of building common ground to approach the issue, developing reflexivity, 'bridging' internal interactions and creating project commitment".

In the next section we further elaborate and embed these five aspects in literature on interdisciplinary research.

\subsection{Five aspects of interdisciplinary research}

The first aspect that comes forward in literature on interdisciplinary working is 'knowledge integration' (Wagner et al, 2011; Klein, 2008; Huutoniemi et al, 2010). Regarding interdisciplinary research the various academic disciplinary approaches are integrated. Holbrook (2013) argues that in much literature on interdisciplinary research hold the premise that disciplines can be integrated, whereas it also important to recognize the possibility of incommensurability among disciplines. Interdisciplinary research also demands reflexivity and invention of a new shared language (Holbrook, 2013). Bruce et al. (2004) note that the start-up phase of interdisciplinary projects takes long. "This means not prematurely reducing a problem to a limited set of dimensions, but taking time to explore a range of dimensions, to test several potential boundaries to a problem [...] until the apparently optimum boundary and set of dimensions has been identified" (Bruce et al., 2004: 465). In an interdisciplinary group researchers thus need to distribute and share their ways of knowing with others. An important step here is the exploration of how different involved researchers approach and 'know' the problem or issue. A next step is that the different knowledge sources are attuned and even integrated in new information and knowledge (Edelenbos et al., 2011).

The second element is the existence of 'common ground' (Huzair et al, 2010; Huutoniemi et al, 2010). Team members need to develop synthesis together, and

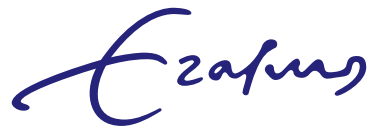


for that they need a common vocabulary and shared understanding of objectives, possibilities, limitations, and so on (e.g. Klein, 1990: 188-189; O'Brien et al, 2013). The development of a common vocabulary is considered one of the core challenges in interdisciplinary working due to the different disciplinary frames (Klein, 1990; Petts et al., 2008). Another important aspect in establishing common ground in interdisciplinary work is to come to some kind of joint framework (e.g. Klein, 1990: 188-189). A joint working plan, a common agreed upon method or an accepted theory can be such a joint framework (Petts et al., 2008). Through these frameworks information and knowledge exchange can be facilitated. Developing a common vocabulary and a joint framework to approach the project requires (and/or facilitates) a reciprocal learning process and building and maintaining communication through integrative techniques (Lyall et al, 2013). It also demands developing mutual understanding between the different researchers in the interdisciplinary group (O’Brien et al, 2013).

The third element we distinguish from the literature is the existence of 'reflexivity' (Bruce et al, 2004; Lyall et al, 2013; Klein, 1990; Holbrook, 2013). Interdisciplinary work demands for certain capacities and capabilities of the team members, such as flexibility, receptivity and sensitivity to others (Klein, 1990). "Since interdisciplinarians are often put in new situations, they must know how to learn. They need to know what information to ask for and how to acquire a working knowledge of the language, concepts, information, and analytical skills pertinent to a given problem, process, or phenomenon." (Klein, 1990: 183). Reflexivity is sometimes stressed as a prerequisite for integration of disciplines because adaptation of scholars is required to explore and find a new language (Holbrook, 2013). Skills as differentiating, comparing, contrasting, relating, clarifying, reconciling, and synthesizing are required. Having these capacities and capabilities will allow them to actually be able to engage in interdisciplinary working, as just wanting to do it is not enough. A reflexive attitude allows for these skills as it includes values as openness to others and willingness to adjust existing frames and behavioral modes (Marzano et al., 2006; Petts et al., 2008). Because of the presence of different disciplinary frames, an important prerequisite for the implementation of interdisciplinary research is openness and willingness to learn from other disciplines. Serious difficulties are experienced in practice in this matter (e.g. Bruce et al., 2004; Haapasaari et al., 2012). Participants have to be open and willing to learn from each other and to see the value of other disciplinary frames (c.f. Haapasaari et al., 2012). Podesta et al (2013) add that personal characteristics as patience, empathy, and humility are important in creating self-reflective capacity.

The fourth element is 'bridging internal interactions', with which we mean the way communication and interaction between the team members facilitates and stimulates researchers to step down from the ivory tower (Bruce et al, 2004; Klein,

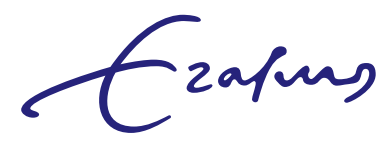


2008). A first relevant aspect here is simply the frequency of interaction and contact: actors that interact more frequently are more likely to share knowledge. However, what is also important in interdisciplinary work is that actors share knowledge across organizational or disciplinary boundaries (see above). This means also the diversity or variety of interactions is important in this respect. More diverse interactions can facilitate and stimulate bridging organizational boundaries (Reagans and McEvily 2003). This means more and diverse interaction patterns will facilitate interdisciplinary work. Another aspect that is important here is the role of informal interaction. As Chevrier (2003: 146) notes: “[...] strategy for coping with cultural differences is to make team members become well acquainted with one another. [...] Social events like diners [...] Personal relationships enable effective mutual agreements." Chevrier does add a word of caution: (informal) interaction is no panacea, because different contexts can lead to different outcomes: frequent cooperation and interaction may result in better mutual understanding, but it can equally lead to a reinforcement of negative stereotypes or assumptions about the other (2003: 148). Finally, in terms of 'bridging internal interactions' also face-to-face communication is an important aspect. Face-to-face communication facilitates information exchange and is especially important in the exchange of tacit knowledge (Asheim et al., 2007). Furthermore, it is highly important for building trust, exchanging mutual commitment and building a group identity. Face-to-face dialogue "is at the core of the process of breaking down stereotypes and other barriers to communication [...]. It is at the heart of a process of building trust, mutual respect, shared understanding, and commitment to the process" (Ansell and Gash, 2008: 558). This is considered to be important for interdisciplinary research in which people from different disciplines not seldom hold stereotypes or negative images about the added value or approach of other disciplines (see for example Haapasaari et al., 2012). Interdisciplinary work thus requires both frequent bilateral as well as multilateral (team-wide) interactions, combined with informal interaction during for instance project dinners, with the result that team members are satisfied about the degree and effect of their interactions. Face-to-face communication and constructive dialogue are important in this regard. Marzano et al. (2006) note that a combination of informal, team building events and meetings/workshops is important for enhancing mutual understanding and developing trust.

The fifth core element is 'project commitment'. This entails both the personal commitment and the commitment of the team as a whole to the interdisciplinary project. A successful interdisciplinary project needs researchers that are personally committed to the project or 'ambassadors' that are willing to go the extra mile for it and undertake the extra effort of engaging with other disciplines (Gray, 2008; Klein, 2008). These ambassadors organize workshops and facilitate communication and interaction between the disciplines (Gray, 2008). Personal meaning of the

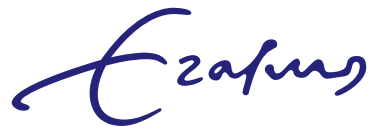


project is crucial in that regard. This concerns the importance and meaning project partners personally attribute to the project, and whether they personally feel as part of the team, etcetera. The more personal meaning and motivations people feel for the project, the more likely they will put much effort in the project and the interdisciplinary working. Another aspect here is the commitment of the team as a whole to make the interdisciplinary project a success. Team commitment is about the "shared commitment of members to achieve a goal that requires the collective effort of the group" (Van den Bossche et al., 2006). This is not about unanimous consent but about the joint effort of all actors to reach the project's ambitions.

\section{RESEARCH METHODS}

\subsection{Data collection}

In our case study of the interdisciplinary work in the BRAINPOoL project, we assessed each of the five aspects of interdisciplinary research with a combination of research techniques. Our data was mainly collected through a web-based survey among the team members of the BRAINPOoL project. This survey was executed three times during the duration of BRAINPOoL: once in April 2012, in April 2013 and in April 2014. Survey questions recurred in each survey round, allowing us to map the evolution of the interdisciplinary work in this project (team). An e-mail was sent to all project team members of BRAINPOoL to invite them for the survey. The BRAINPOoL project team consisted of a group of 11 people in total, representing five organizations. Each survey round, we received responses from at least one member of each involved organizations. In 2012, 9 members took part in the survey; in 2013 we received 6 responses and in 20148 responses.

We did not rely solely on the survey for our analysis. We complemented our data collection with participant observation during the entire duration of BRAINPOoL. We took part in all major project meetings and activities of BRAINPOoL. This combination of the survey with participant observation increases the validity of the results. We believe that participatory observation is essential to be able to interpret findings from e.g. surveys, as many aspects of interdisciplinary working are 'soft' and not directly measurable in a survey (Shore and Cross, 2005). Moreover, the participatory observation gave depth to our understanding and knowledge that arose from the survey.

We further used additional research techniques for collecting data on the interdisciplinary work in BRAINPOoL. We held explorative interviews with all project team members (11 team members in total, see above) about their perspective on the project in 2012 and engaged in many informal conversations with BRAINPOoL team members about the way they felt the project was going, what they liked or did

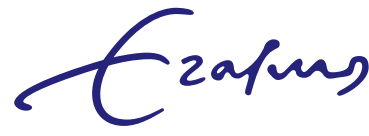


not like, and how they felt about (aspects of) interdisciplinary working. Next to the participant observation, the data collected through these explorative interviews and informal talks gave us additional guidance in interpreting the survey findings.

\subsection{Conceptualization}

To measure the five aspects of interdisciplinary work, we further conceptualized and operationalized each of these aspects into logically matching indicators and items. We based the selections of these indicators and items predominantly on different existing operationalizations and items applied in studies on team processes (see Dietrich et al., 2010; Drach-Zachavy and Somech, 2001).

Table 1. Overview of conceptualization and operationalization of core elements

\begin{tabular}{|c|c|c|}
\hline Core elements & Conceptualization & Indicators/items \\
\hline \multirow[t]{3}{*}{$\begin{array}{l}\text { Knowledge } \\
\text { integration }\end{array}$} & Exploration of different ways of knowing & $\begin{array}{l}\text { Use of different opinions and knowledge } \\
\text { sources }\end{array}$ \\
\hline & \multirow[t]{2}{*}{ Attuning of different knowledge sources } & $\begin{array}{l}\text { Establishment of connection/interchange } \\
\text { between different work packages }\end{array}$ \\
\hline & & $\begin{array}{l}\text { Satisfaction with interchange between } \\
\text { different work packages }\end{array}$ \\
\hline \multirow[t]{3}{*}{ Common ground } & Mutual understanding & Satisfaction with mutual understanding \\
\hline & Common vocabulary & Sharing common language \\
\hline & $\begin{array}{l}\text { Common agreed upon plan/integrative } \\
\text { framework }\end{array}$ & $\begin{array}{l}\text { Joint development of a common/ } \\
\text { integrative plan }\end{array}$ \\
\hline \multirow[t]{2}{*}{ Reflexivity } & Reflexive dialogue & Reflection on team's processes \\
\hline & Sensitivity and openness to others & Discussing problems and tough issues \\
\hline \multirow[t]{3}{*}{$\begin{array}{l}\text { Bridging internal } \\
\text { interaction }\end{array}$} & Frequency of contacts within project team & $\begin{array}{l}\text { Frequency of formal/informal contact } \\
\text { between team partners (bilaterally) }\end{array}$ \\
\hline & Diversity of contacts within project team & Diversity of contact between team partners \\
\hline & Internal communication & Satisfaction about internal communication \\
\hline \multirow[t]{5}{*}{ Project commitment } & Personal commitment & Personal meaning of the project \\
\hline & & Being ambassador for the project \\
\hline & & Feeling part of the project \\
\hline & Team commitment & Experienced team commitment \\
\hline & & Satisfaction about commitment \\
\hline
\end{tabular}

In a next step, we formulated statements based on the distinguished indicators in order to be used for the survey. This survey was set out three times during the project, in which the team members scored the statements each time. Team members were asked to rate these statements according to a scale of 1 to 5 . The scores suggest the following appreciations concerning the presented indicator: scores 1 to 2 as very negative ( $<2$ as very negative), scores 2 to 3 as negative ( $<3$ as negative), 
score 3 as neutral ( $=3$ as neutral), score 3 to 4 as moderate to positive ( $<4$ moderate to positive), and scores 4 to 5 as positive to very positive towards the associated item ( $>4$ as positive to very positive). For instance, if the statement on the item 'use of different opinions and knowledge source' was scored as 3.5, we considered this as a moderately positive opinion about this aspect in the project team.

\section{CASE ANALYSIS}

In analyzing the evolution of interdisciplinary working in the project, we use the following structure. We start each core element section with a text box, which, in short, summarizes our main conclusions on that core element of interdisciplinary work. Then we present one or more figures that display the evolution in mean scores on the items of the given core element, as assigned by the project team members in 2012, 2013 and 2014. We then discuss these scores in an in depth report and further complement the survey findings with findings from our observations, interviews and informal talks

\section{Knowledge integration}

In the early stages of the project (Oct. 2011-March 2012), survey findings show how project partners were moderately positive about the exploration of different ways of knowing (Score 3.33). This finding is supported by our observations during that period: although some efforts were made during project meetings in October 2011 and January 2012 to explore the different ways of knowing, the project team - partially due to time constraints - did not really bottom out the different views and approaches of the project partners. The first explorations remained rather superficial. In the explorative interviews, project partners spoke about a "pragmatic solution": the project team initially decided to work around the differences rather than

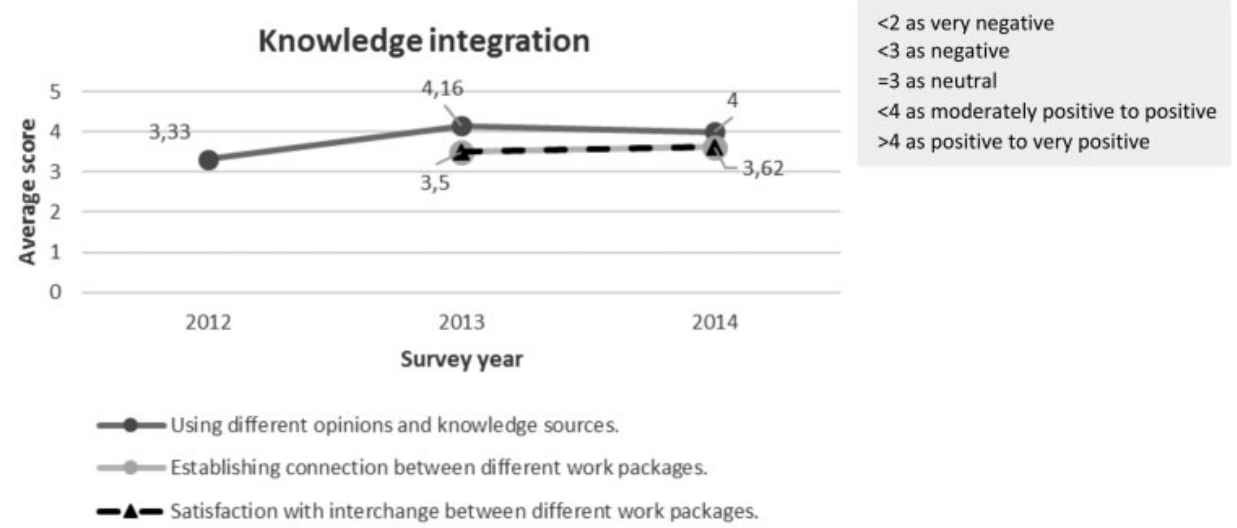

Figure 1. Evolution of Knowledge integration. 
trying to overcome them. This shows how the team, in this stage of the project, only got superficially to the exploration of different ways of knowing. This also meant that, in this initial phase of the project, there was little attention for attuning the different approaches.

By mid-2013, the team was more positive about the exploration of different ways of knowing. The score on this aspect significantly increased between 2012 and 2013 (from 3.33 to 4.16). Additional items in the survey of 2013, measuring whether the team also succeeded in attuning these knowledge sources showed a somewhat more nuanced image. The team had indeed grown in terms of exploration, but still scored rather moderately positive in terms of attuning (score 3.5). Our observations supported these survey findings. The Advisory board ${ }^{1}$ - assigned to follow up the project from the side-lines - called for further attuning the different views and approaches into a joint ambition. Following the advice of the Board, the team spent. A full day to bring the assumptions and different ways of knowing of the involved partners to the table and to discuss how to connect those different approaches into a joint model of what the project should be about. However, there were still no clear agreements and decisions on what the central focus or impact of the project should be. The team made a step forward in terms of exploration of different ways of knowing, but not in attuning different knowledge sources. Knowledge integration thus especially improved in terms of exploring, but remained at a modest level in terms of attuning.

In 2014, the team judged all aspects of knowledge integration somewhat similar as in 2013 (for exploration of different ways of knowing: 4.16 in 2013, 4 in 2014; for attuning different knowledge sources: 3.5 in 2013 to 3.62 in 2014). The project team still experienced exploration as positive, and remained only moderately positive about the level of attuning within the team.

\section{Common ground}

Survey findings of 2012 show how project partners were rather cautious in their assessment of sharing a common language and of mutual understanding within the project team: their judgment was neutral to moderately positive (score 3 and 3.11 respectively). In the open answers, one of the project partners remarked how the project team, in this phase of the project, struggled with "some misunderstandings in terms of terminology, language, and intentions". During meetings, we observed

1. The Advisory Board of the BRAINPOoL project consisted of acknowledged experts in the field of alternative indicators, being able to follow the progress of the project and provide advice. The BRAINPOoL project team met about 4 times with the Advisory Board throughout the project. The Advisory Board was established to: “(a) ensure the project's objectives are met, (b) the ideas will be evaluated by another high-level forum, (c) the practical ideas of the project are reviewed, discussed and evaluated themselves, and (d) implementation of the recommendations is made easier." (Description of Work, 2011: 21).

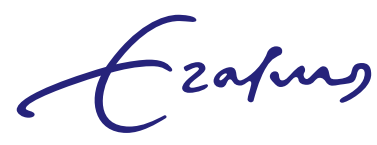




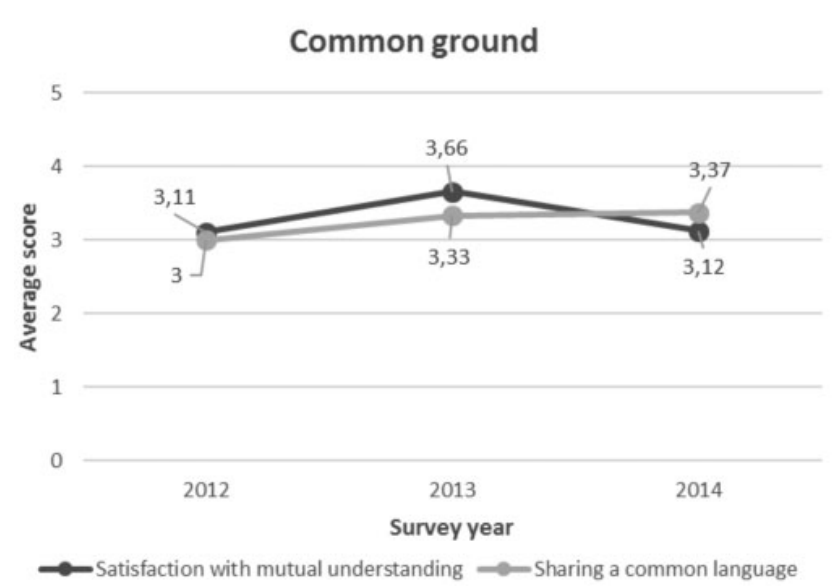

$<2$ as very negative

$<3$ as negative

$=3$ as neutral

$<4$ as moderately positive to positive

$>4$ as positive to very positive

Figure 2. Evolution of Common ground.

heated discussions about concepts and terminology used (e.g. there was quite some discussion about the conceptual distinction between the term 'users' and 'producers'), showing how the project team somewhat lacked a common language to approach the project. Following these conceptual discussions, the project team decided to make a common 'glossary' so that concepts could be used in the same manner. Project partners indicated that mutual understanding and common language were not well developed at that time and how both still needed to develop in the time to come. At the same time, project partners indicated how they were confident that all this would automatically grow over time and that they would find a way to overcome differences in approach, logic and language.

Despite the expectations expressed above, in later measurements project partners assessed sharing a common language and mutual understanding only slightly more positive than in the initial phase of the project. However, their judgment was still rather moderately positive than positive (score 3.33 and 3.66 respectively). During the project meetings in this phase of the project (September 2012, Prague; Delft 2013; Delft) we saw how discussions on objectives, concepts and terminology continuously recurred. During the meeting in September 2012, the advisory board called for the development of an overall framework. In this phase of the project, the project team continued its search for common ground. However, the previously discussed idea of a 'common glossary' did not really get off the ground as no one really took the lead in this. On the other hand, we also observed how these discussions were now less fraught with misunderstandings than before. Project partners were more aware about each other's approach to the project and, in our opinion, demonstrated more understanding for each other's logic. This is in line with the higher score for mutual understanding in the 2013 survey (3.66 in 2013). 
In the last phase of the project (March 2013-March 2014), again sharing a common language and mutual understanding were judged as moderately positive (3.12 and 3.37 respectively). Mutual understanding even fell back to its initial score in 2012 - which indicates a slight decrease. Observations of the project meeting (September 2013, Berlin) and project activities in this period (October 2013, Workshop Venice; March 2014, Final Conference Paris) showed how conceptual agreement and developing a common language remained difficult to accomplish. Again and again attempts to attune WPs stirred up conceptual discussions. This also became visible when the project team discussed the report on WP3, which, despite earlier agreements on concepts, used different conceptualizations than the report on WP2. The above findings show that, at the final stage of the project, the project team still had not succeeded in establishing a well-developed common ground.

\section{Reflexivity}

Survey results of 2012 on reflexivity were somewhat ambivalent. Reflexive dialogue, on the one hand, was judged moderately positive (score 3.11). Project partners were not all too enthusiastic about this aspect, but not negative either. On the other hand, openness and sensitivity were assessed as very positive (4.11). This positivity also came forward in the open answers in the survey. Project partners wrote about a "good atmosphere to be open and honest to each other in our communication", and "quite open discussions". During the first project meetings (October 2011; September 2012), we observed that the group was clearly searching for common ground, but at the same time there was the urge to move forward rather than taking time for reflection on the choices made. This may explain why reflexive dialogue was assessed as rather moderate.

In 2013, project partners evaluated both aspects of reflexivity somewhat better than in 2012. Again, they mentioned the open atmosphere within the project team. Project partners experienced the project team as "receptive" and "responsive" and

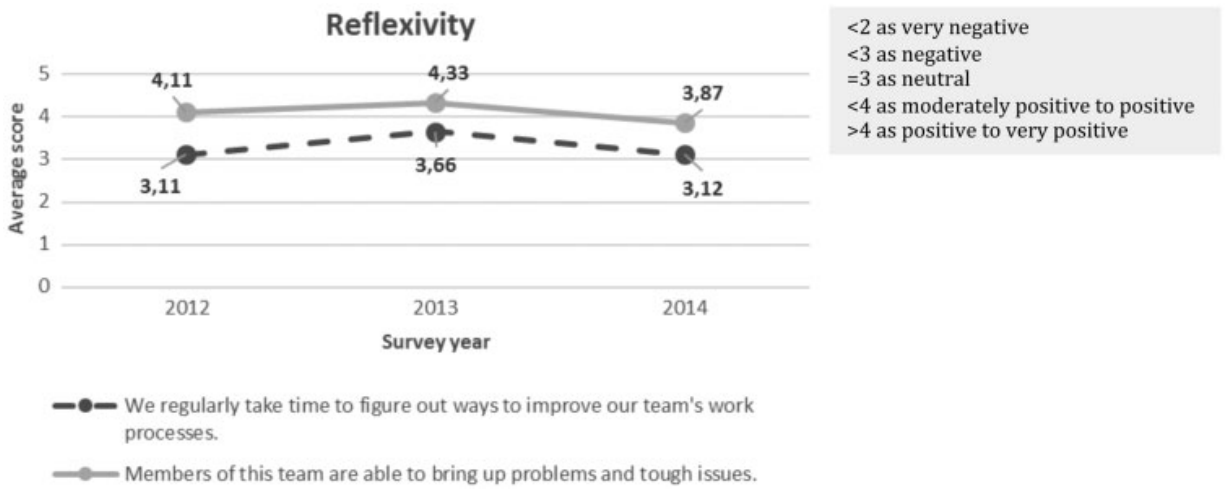

Figure 3. Evolution in Reflexivity. 
indicated how they experienced the meetings as a "great place to talk and think together". Also, reflexive dialogue was judged slightly more positive than in 2012. However, the score on this aspect was still moderately positive. During the meetings in this phase of the project, we observed how the group worked together in an open and constructive way. Thanks to the push of the advisory board during the project meeting in September 2012, we also saw how the project team took more time to reflect on the choices made and the actions taken within the project. This is in line with the slight increase in reflexive dialogue.

Survey scores on both aspects of reflexivity were less positive in 2014 than in 2013. In the open answers, project partners mentioned the prevalence of "communication breakdowns" and "offensive reactions" during discussions on one of the WPs (WP4). Some project partners criticized the approach chosen by the WP-leader but had the feeling there was no room for input on the further development and design of the WP. Such remarks indicated how the perceived openness and sensitivity came under pressure. These lower survey scores of 2014 didn't really come as a surprise. By the end of the project, reflexivity - especially in terms of openness and sensitivity - was judged less positive than in the early and middle stages of the project.

\section{Bridging internal interactions}

During the first year of the project, interactions between project partners were both frequent and diverse, this especially applies to the bilateral contacts between project partners and less so to the multilateral contacts. During this phase of the project, the team had two project meetings in which there were multilateral and face-to-face contacts. Project partners experienced this as the minimum of frequency necessary: "limited to what was essential". This quote suggests that project partners seemed to experience the frequency of multilateral interactions as just sufficient. The team also maintained contact through multilateral mails which

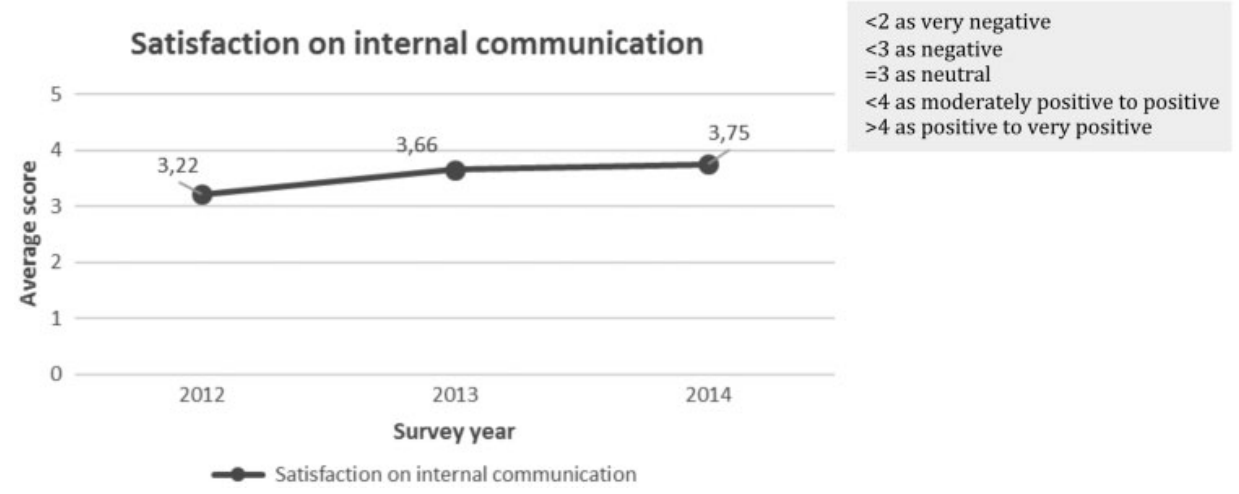

Figure 4. Evolution in satisfaction on internal communication. 
project partners experienced as an "efficient" way of working. The survey findings of 2012 reveal how, in the early stages of the project, bilateral contacts were quite frequent. All partners maintained at least monthly contacts with each other. However, the survey findings also showed how frequency of contacts was higher between partners cooperating within the same WP compared to the frequency of contact with partners of other WPs. During informal moments we also observed how partners working together in a WP, were more drawn to each other. At this stage of the project, the overall internal communication was judged as rather moderately positive (score 3.22).

In the second phase of the project, between March 2012 and March 2013, the frequency of multilateral, face-to-face contacts remained similar to that in the previous phase. In this phase, project partners however indicated how their mutual interactions missed regularity and coordination, they said to experience a "lack of regular communication" and "no masterplan to coordinate interaction". This suggests project partners were somewhat less satisfied with the frequency or regularity of the multilateral interactions, and in what way this was fostered by the process facilitator (main applicant of the project). Despite the critiques mentioned above, the overall internal communication was judged more positive than in 2012. Interactions were mostly concentrated around project partners that were actively involved in the WP under discussion. However, during informal contacts - for instance project dinners - we now saw more interactions across institutions and across WPs.

In the final phase of the project, we saw a similar image as in the previous phases. Again, the project team had two project team meetings in which they had face-to-face, multilateral interactions. Although these interactions were as frequent as before, open answers suggested that the frequency of these multilateral interactions in this last phase of the project did not suffice. Project partners indicated how "communication got lost", how they experienced difficulties to keep everybody "in the loop" and how the lack of face-to-face meetings in the final stage hampered the communication on the last WPs. All this suggests that the meetings that were initially experienced as frequent enough now were experienced as insufficiently frequent - although frequency itself did not change. This can - at least partially - be explained by the fact that the work package work in the remaining year required more multilateral interaction and alignment than in the first project period, as a final integral document had to be made. Concerning the frequency of bilateral contacts, the image of the earlier phases is reaffirmed. There is a big 'however' though. The satisfaction with internal communication increased throughout the project duration. This shows how, although communication between partners was not flawless and there were suggestions made for its improvement, project

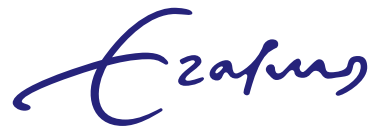




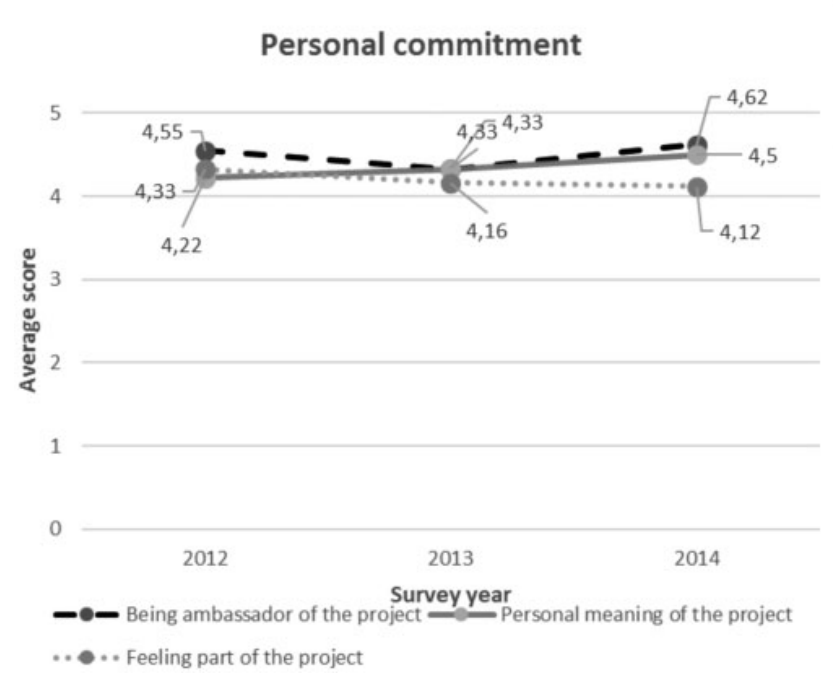

$<2$ as very negative

$<3$ as negative

$=3$ as neutral

$<4$ as moderately positive to positive

$>4$ as positive to very positive

Figure 5. Evolution in Personal commitment.

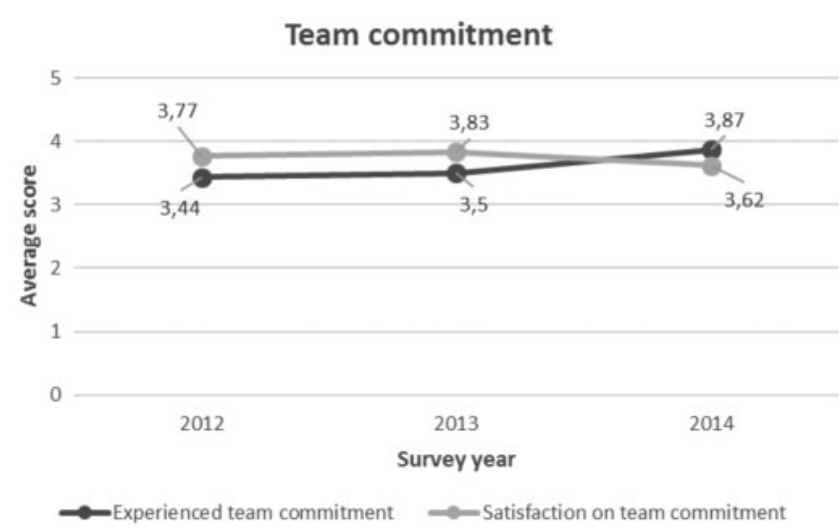

$<2$ as very negative

$<3$ as negative

$=3$ as neutral

$<4$ as moderately positive to positive

$>4$ as positive to very positive

Figure 6. Evolution in Team commitment.

team members remained positive about the overall internal communication and their satisfaction even gradually improved throughout the project.

\section{Project commitment}

From the beginning on, in 2012, project partners indicated how they felt strongly committed to the project. Scores were high on all items in terms of personal commitment. In this phase, the score on team commitment was not as overwhelmingly positive. Project partners were moderately positive (scores 3.44 and 3.77) in their judgement on this aspect. In the open answers project partners described the team as follows: "very much committed", a team with a "general positive commitment". 
At the same time, project partners questioned whether this applied to the whole team. One project member remarked that there was "some disequilibrium among us" in this respect. Also in the explorative interviews, we heard how project partners were very motivated and had a drive to make the project a success. In terms of team commitment project partners remained more on the surface, they especially sketched how the project team was defined by the lack of mutual understanding (see earlier). Improving this was seen as important to improve and maintain team commitment in the future.

Survey findings of 2013 reaffirmed the positive image on personal commitment. Also in this phase of the project, project partners kept feeling strongly committed to the project. This is especially true for the personal meaning the project has for themselves. The other two aspects were judged somewhat less positive than in 2012, but the score remained positive overall. Judgment on team commitment remained more or less stable. Again, project members indicated in the open answers how they experienced the team as "truly sincerely committed". Despite these positive words, judgment on this aspect remained at a moderately positive level in 2013.

In 2014, survey findings again showed how project partners felt strongly committed to the project. Again, we saw high scores on all components of personal commitment. The upward trend in terms of experienced team commitment persevered in 2014. In the open answers team members indicated how they had the feeling team commitment was high in this final phase of the project. However, in the last survey, project members also complained about the passive attitude of some project partners during project activities in this phase. In the open answers, they also said to feel less team commitment than before. This probably explains the ambiguous judgment in terms of team commitment: this aspect was judged more positive in this phase, but project members were less satisfied with it.

\section{DISCUSSION: FACTORS INFLUENCING THE EVOLUTION OF INTERDISCIPLINARY WORKING}

In the previous section, we have scored each of the items attached to the five core elements we defined in the beginning of this article. In BRAINPOoL we initially witnessed a positive start, with high hopes, but also some reservations. During the second measurement, we generally witnessed more positivity and satisfaction with the different components of interdisciplinary working. In this phase, project team members were generally positive about the interdisciplinary work within the team. However, during the third and final measurement, this upward trend somewhat stagnated or, for some elements, even reversed: many items were scored lower again; falling back to starting levels or even below. It seemed as if, in the second and third year of the project, the project team touched upon

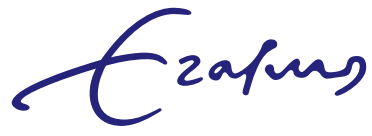


the limits of interdisciplinary working. Although it is important to note here that the differences in scores are small, it is noteworthy to see how this trend occurs in almost half of the measurements. What is also important to note is that none of the scores dipped to a low or negative level, even if decrease occurred. The scores remain moderately positive (averaging $>3$ ) to positive $(>4)$. This means that, within this project, interdisciplinary working reached a basic level but only improved piecemeal throughout the project. This led us wondering, what factors caused this evolution of interdisciplinary working? In the paragraph below, we shortly review each element's evolution and then elaborate on the factors that - in our opinion - contributed to this evolutionary pathway. For each conceptual component, we discuss the factors that stimulated or impeded further interdisciplinary working.

\section{Knowledge integration}

During the first year of the project, the team progressed significantly in terms of knowledge integration. An important stimulating factor herein was the Advisory Board (further referred to as $A B$ ). During the first year and a half, the team met twice with the $A B$. During these meetings, the $A B$ took the role of critical observer: board members critical questioned the choices made in the project, asked for conceptual clarification and reflected on the results so far. Doing so, the AB created a setting in which the group could take some distance from its own work and look with new eyes to the project. This helped to get everyone in a more reflection-oriented modus and led to awareness of the diverging views and images that still resounded in the project team's ideas. As such, discussions with the AB contributed to a further search for integration of the different knowledge sources.

Although the project team showed to be capable to explore the different knowledge sources, it was hard to come to more in-depth integration of these knowledge sources. At least two factors seemed to impede further-reaching integration. First, during the project, it became clear that the project preparation, as written down in the Description of Work ${ }^{2}$ (further referred to as DoW), still left quite some room for different interpretations. This meant that, once the project started, the project team members had quite some issues to discuss and clarify and still needed time to find alignment on these issues. An example of this was the confusion concerning the contents and approach of one of the core WPs of the the BRAINPOoL project. Halfway during the project there were still fierce discussions about how this WP should look like, what was part of the WP and what was not, etcetera. A second explanatory factor for the stagnation of knowledge integration in the BRAINPOoL

2. The Description of Work (DoW) contains the details of the implementation of the project with regard to the work packages, deliverables, milestones, resources and costs of the beneficiaries - organized in a table format - as well as a detailed narrative description of the work.

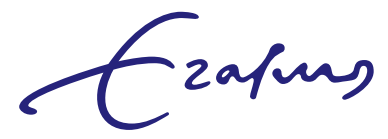


project are the disciplinary differences between the members. The team consisted of members with quite different disciplinary backgrounds. Three partner organizations were universities, two were independent think tanks and one organizations was a consultancy/research firm. In general, the big disciplinary difference or gap was between those members with an academic focus, i.e. the three universities, and those with an advocacy, action-oriented focus, i.e. the independent think tanks, towards the project. The first group, the academics in the project, was more concerned about developing clear conceptualizations and gaining understanding about the drivers and barriers in the adoption of a well-being focus in government policy and society. This group had an epistemological orientation (Huutoniemi et al, 2010: 85), and was - as such - more concerned with developing more systematic and profound scientific understanding and knowledge of the phenomenon. The second group, the advocates, was more oriented towards bringing about change and to identify potentials and pitfalls in government institutions and society to pursuit a well-being orientation. The advocacy group had an instrumental orientation (Huutoniemi et al, 2010: 85), implying that this group was more focused at solving social problems or developing commercial products. As such, the advocacy, more action-oriented focus towards the project, pursued by the two independent thinktanks, conflicted with the academic focus (academics). Tensions grew between the two groups regarding the central aim of the project. Whereas the academics were preoccupied with systematically broadening understanding and knowledge on the topic, the advocates were more preoccupied with how to use existing and emergent knowledge to bring about change in policies. These diverging orientations revealed how both groups often wanted to move at a different pace: the advocacy group, aiming for change, wanted to move forward, beyond knowledge gathering, while the academic group attached great importance to systematic and careful research. Furthermore, the advocacy group had more explicit norms and beliefs underlying the research activities; whereas the scientific group approached the research topic more neutral (Campbell, 2005).

\section{Common ground}

The establishment of common ground did not improve all too much throughout the project (scores persisted around 3 to 3.6 at its best). However, during the second year of the project, there was a slight highlight in terms of mutual understanding. This progress, albeit modest, is for a great deal due to the efforts of the project leader and his informality-oriented leadership style, oriented at facilitating informal contacts between the project partners. The project leader made sure that there was time and space for informal contacts - during dinner, drinks, coffee breaks and etcetera. During these more informal moments, project partners became more acquainted and we observed how this informality also improved the atmosphere at the meeting

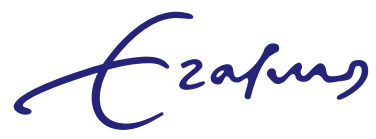


table. The more open and loose nature of these informal talks helped project partners to get appreciation of each other's thinking. These informal opportunities thus contributed greatly to maintaining an overall good atmosphere in line with the analysis of Chevrier (2003: 146) mentioned in section 2.2. It also contributed to maintaining a basic level of common ground and mutual understanding. This connects to the important role of 'minimal familiarity' in teamwork: a basic level of informality is necessary to preserve trust and interdisciplinary teamwork (Wagner et al, 2011).

However, scores on common ground and mutual understanding did remain on a moderate level. We believe two factors impeded further development of common ground within the project team. First, as for the progress in knowledge integration, we saw how disciplinary differences somewhat stood in the way of developing common ground. As pointed out above, partners had quite some diverging ideas about the core objective of the BRAINPOoL project; was the project about gaining more knowledge and understanding or about bringing about change in government policy and society? This hampered the establishment of common ground. Second, and related to the first, the rather moderate scores on common ground and its stagnation after the second project year can also be explained by the fact that leadership became somewhat contested throughout the project. The project leader was not an expert on the project topic and focused on project management, in a pragmatic way. This pragmatic approach sometimes conflicted with the more idealistic approach of some of the expert partners. These disagreements had their effects on the project team and, as a result, the level of common ground did not reach higher levels.

\section{Reflexivity}

Reflexivity within the team initially increased and, as already pointed out earlier, the discussions with the $A B$ definitely contributed to this initial progression of reflexivity. A more striking development of reflexivity however is its decline in the last phase of the project. We see one important explanatory factor for why the project team did not succeed in maintaining a higher level of reflexivity. In the second and final stage of the project, the project leader became more task-oriented (focus on 'getting the job done') and as such left little space and time for more reflexive discussion. The project leader's first concern was, as he said, "to check the boxes" and meet the objectives as formulated in the DoW. This implied that there was less room for reflecting on past results and for discussing about possible alternative ways of working.

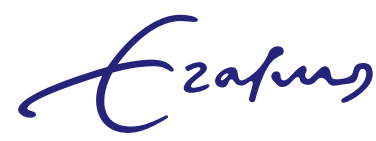




\section{Bridging internal interactions}

Throughout the project, satisfaction with internal communication gradually grew. We attribute this steady growth to at least two factors: the professional conduct of the project partners and the informality-oriented leadership of the project leader (see earlier). Concerning the first, we saw that internal interactions in general went smoothly. Project partners communicated in a professional way with each other: they showed respect for each other during meetings, listened and reacted adequately to others' contributions. Second, also the project leader did his share for improving internal communication. His attention for informality in the project was very helpful to create a relaxed, open atmosphere.

In contrary to the improved satisfaction about the internal communication, we saw little improvement in terms of the development of bridging internal interactions. At least, bridging interactions did not reach further than that within WPs. We believe this is partially due to the structure of the DoW. The DoW describes the work process and divides the different tasks and responsibilities (divided in WPs) to different partners. So, it is inevitable that the interdisciplinary group falls apart in subgroups working together on specific tasks. To a certain extent, the DoW thus coordinates and facilitates interdisciplinary work, but, at the same time, it also sets boundaries to interdisciplinary work and restricts it to the work done in subgroups. This kind of working facilitates efficient working, but at the same time hampers real integration of work and therefore interdisciplinary working.

\section{Project commitment}

The image of the project commitment's evolution is somewhat ambiguous. On the one hand, we saw how team members felt highly committed to the project. They also experienced the team commitment (team as a whole) as truly committed. From the outset, it was clear that team members cared about the project. They shared an interest and even passion for the theme and were determined to make the project a success. Once results, such as reports, were realized, around the second year, team commitment further increased. On the other hand, however - a somewhat confusing result from the survey - was that feeling part of the project and satisfaction on team commitment both decreased. Different factors played a role herein. First, as already pointed out, disciplinary differences created barriers to the development of mutual understanding between team members. These differences created misunderstandings and sometimes even fundamental disagreements about approaches to the project (see earlier). Another factor that hampered further development of team commitment was the division of work in WPs (see above). As the project progressed and the work of certain WPs ended, this meant that certain team members had more or less completed their role in the project. For some of them this led them to be less involved in the work still to be done. As a

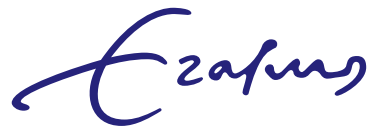


result, there was less general interaction among the team members leading to less interdisciplinary working.

In table 2, we present an overview of the different factors we found explanatory for the evolution of interdisciplinary working in BRAINPOoL.

Table 2. Overview of stimulating/impeding factors for evolution interdisciplinary working

\begin{tabular}{|c|c|}
\hline $\begin{array}{l}\text { Advisory Board } \\
\text { as critical observer }\end{array}$ & \multirow{3}{*}{$\begin{array}{l}\text { Knowledge integration } \\
\text { Slightly improved, then stagnated. }\end{array}$} \\
\hline $\begin{array}{l}\text { Project preparation / DoW } \\
\text { loose ends }\end{array}$ & \\
\hline $\begin{array}{c}\text { Disciplinary differences } \\
\text { different disciplinary backgrounds }\end{array}$ & \\
\hline $\begin{array}{l}\text { Leadership style } \\
\text { informality }\end{array}$ & \multirow{2}{*}{$\begin{array}{l}\text { Common ground } \\
\text { Little improvement throughout project. }\end{array}$} \\
\hline $\begin{array}{c}\text { Disciplinary differences } \\
\text { different disciplinary backgrounds }\end{array}$ & \\
\hline $\begin{array}{l}\text { Advisory Board } \\
\text { as critical observer }\end{array}$ & \multirow{2}{*}{$\begin{array}{c}\text { Reflexivity } \\
\text { First increased, then decreased. }\end{array}$} \\
\hline $\begin{array}{l}\text { Leadership style } \\
\text { task-orientedness }\end{array}$ & \\
\hline Professional conduct & \multirow{2}{*}{$\begin{array}{l}\text { Bridging internal interactions } \\
\text { Satisfaction gradually improved. } \\
\text { Little improvement in 'bridging' } \\
\text { interactions. }\end{array}$} \\
\hline $\begin{array}{c}\text { Project preparation / DoW } \\
\text { division of tasks and responsibilities }\end{array}$ & \\
\hline Heart for the project theme & \multirow{3}{*}{$\begin{array}{c}\text { Project commitment } \\
\text { Personal commitment remained high. } \\
\text { Team commitment first increased, then } \\
\text { decreased. }\end{array}$} \\
\hline $\begin{array}{c}\text { Project preparation / DoW } \\
\text { division of tasks and responsibilities }\end{array}$ & \\
\hline $\begin{array}{c}\text { Disciplinary differences } \\
\text { different disciplinary backgrounds }\end{array}$ & \\
\hline
\end{tabular}

\section{CONCLUSION}

In this article, we wanted to contribute to the evolutionary understanding and explanation of interdisciplinary working, as this is a relatively undiscussed topic. In our case study of the interdisciplinary, EU-funded BRAINPOoL project we found that interdisciplinary working is not a static process, but is a very dynamic process with ups and downs. We have conceptualized interdisciplinary working in five key aspects: commitment, common ground, cross-boundary interaction, reflexivity, and knowledge integration and analysed those aspects in a real-life project. Each of these five aspects has its own dynamics all - in sum - affecting the evolution of interdisciplinary work. The dynamic nature of interdisciplinary working is mentioned in some literature (Podesta et al, 2013; Wagner et al, 2011), but is not yet opened up and (micro-) analysed in empirical research. We believe our study 
has contributed to an increased understanding of the dynamic nature of interdisciplinary working. At the same time, our study may be limited because of our close involvement in the project. Our role as evaluators may have influenced the evolution of interdisciplinary working as we provided feedback, especially in the first and second phase of the project. Our reviews led to changing expectations and to increasing attempts to interdisciplinary working, especially in the second stage of the project.

A core observation in our study concerning the dynamics of interdisciplinary work is that interdisciplinary work stagnated in the last phase of the project, when project deadlines and ending came near. We observed that especially internal bridging activities and reflexivity severed under time pressures, and this in turn also led to stagnation of knowledge integration efforts. Time pressure pushed out capacities and possibilities to reflect, learn and adapt, and these are important in realizing interdisciplinary research (compare Holbrook, 2013). This observation supports the insight by Podesta et al (2013: 44) that time pressure replaces extended plenary meetings with short tailored meetings between individual members. When the end of interdisciplinary working is near, people are less inclined to develop and maintain cross-boundary collaboration. At the same time, our case study indicated that these three aspects of interdisciplinary working (internal bridging interactions, reflexivity and knowledge integration) were more important for furthering interdisciplinary working than the other two aspects: common ground and commitment, which even can be considered general aspects of multiactor and collaborative engagements and not specific aspects for interdisciplinary working (O'Brien et al, 2013). Our research showed that despite rather positive results on (personal) commitment and common ground, the substantive alignment within the project did not go smoothly and interdisciplinary work thus stagnated. Moreover, although our case study shows that interdisciplinary working was in general positive - all elements were scored moderately positive to positive, some even very positive - it also became clear that it was hard to improve and - more important - maintain the level of interdisciplinary working towards the end of the project. This implies that interdisciplinary working is not self-executive and needs constant attention and nurturing.

However, our research also showed how some specific factors did stimulate interdisciplinary work. This brings us to formulate lessons for policy makers trying to develop and maintain interdisciplinary working. Regarding stimulating knowledge integration and reflexivity, our case study showed the importance of having a kind of Advisory Board that critically monitors and reflects upon the interdisciplinary nature and development in the project and process (compare Lyall et al, 2013). A policy lesson is that it is important to such a board that critically reflects and advices project members in order to further develop and maintain the

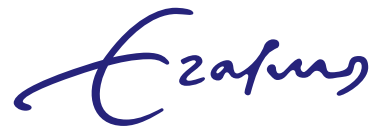


interdisciplinary process. Moreover, policy makers and funding agency officials should also provide the necessary resources - in particular time - for developing knowledge integration and reflexivity and for fostering and maintaining cross-boundary (-disciplinary) interactions. Attention and room for fostering both aspects, reflexivity and bridging interactions, often were supressed by the need to finish things. As well in the first phases of the project, as later on in the project, the need to move forward, to 'check the boxes' prevailed and as such hampered further reflexivity and bridging interactions. This also hampered further knowledge integration. Finally, it is also important to think about how to keep interdisciplinary working alive after the funding period, as we have seen that project deadlines really deliver a problem for continuous collaboration and interaction. A follow up grant can make emerging interdisciplinary working more sustainable, however this does not imply that these projects need to be funded eternally.

In developing and maintaining the level of interdisciplinary working we found that especially factors as leadership and finding a way to deal with disciplinary differences are important. Leading the BRAINPOoL project showed to be a challenging task. In our case study, we observed how the facilitative leadership as witnessed in the first phase of the project dissolved during the second phase and manifested in the third and final phase in conventional project management in which time orientation (reaching a deadline) dominated the process leading to less opportunities for reflection, cross-disciplinary interactions, and knowledge integration. This observation shows that managing an interdisciplinary working process is a delicate balance between stimulating task completion while at the same time keeping everybody on board and accommodating space and time to discuss and reflect on the different ways to approach the project. Especially a certain kind of leadership can be considered important, which is called facilitating and inspiring leadership (Gray, 2008; Klein, 2008; Lyall et al, 2013). This kind of leadership is needed in in all phases of interdisciplinary working, especially regarding the ending as processes then incline to dissolve again in disciplinary orientation and action. Cross boundary and disciplinary leadership proves to be important in generating reflexivity and opportunity and willingness to learn from each other and to see the value of other disciplinary frames (c.f. Haapasaari et al., 2012; Huutoniemi et al, 2010). This is also in line with the work of Podesta et al (2013) that emphasizes patience and empathy as crucial conditions for interdisciplinary working. It takes time to develop and maintain trustworthy relationships between researchers from different disciplines (O'Brien et al, 2013). Creating time and opportunities for reflection are important to explore and to deal with the different disciplinary backgrounds and in turn to get the best out of interdisciplinary projects. 


\section{REFERENCES}

Aboelela, S.W. et al. 2007. Defining Interdisciplinary Research: Conclusions from a Critical Review of the Literature. Health Serv Res. 2007 Feb; 42(1 Pt 1): 329-346.

Ansell, C. and Gash, A. 2008. Collaborative Governance in Theory and Practice. J Public Adm Res Theory (2008), 18(4): 543-571.

Asheim, B., Coenen, L., Vang, J. 2007. Face-to-face, buzz, and knowledge bases: sociospatial implications for learning, innovation, and innovation policy. Environment and Planning C: Government and Policy, 2007, vol. 25, issue 5, pages 655-670.

Barnes, T., I. Pashby, and A. Gibbons (2002), Effective University-Industry Interaction: A Multi-Case Evaluation of Collaborative R\&D Projects, European Management Journal, 20: 272-285.

BRAINPOoL (2011), Grant agreement 283024, Annex I Description of Work (DoW), 29 July 2011.

Bruce A., Lyall C., Tait J., Williams R. (2004) Interdisciplinary Integration in the Fifth Framework Programme, Futures, Volume 36, Issue 4, pp. 457-470.

Campbell, L.M. (2005), Diversity. Overcoming obstacles to interdisciplinary research, Conservation Biology, 19(2): 574-577.

Chevrier, S. 2003. Cross-cultural management in multinational project groups. Journal of World Business, Volume 38, Issue 2, May 2003, Pages 141-149.

Dietrich, P, Eskerod, P, Dalcher D and Sandhawalia B (2010). The Dynamics of Collaboration in Multipartner Projects. Project Management Journal 41(4), 59-78.

Drach-Zahavy A and Somech A (2001) Understanding Team Innovation: The Role of Team Processes and Structures. Group Dynamics: Theory, Research, and Practice 5(2), 111-123.

Edelenbos, J., Van Buuren, A., Van Schie, N. 2011. Co-producing knowledge: joint knowledge production between experts, bureaucrats and stakeholders in Dutch water management projects. Environmental Science \& Policy, Volume 14, Issue 6, October 2011, Pages 675-684.

Gray B. (2008), Enhancing transdisciplinary research through collaborative leadership. Am J Prev Med, 35(2S):S124-S132.

Guimera, R., B. Uzzi, J. Spiro and L. Amaral (2005, Team Assembly Mechanisms Determine Collaboration Network Structure and Team Performance, Science, 308: 697-702.

Haapasaari P., Kulmala S., and Kuikka S. 2012. Growing into interdisciplinarity: how to converge biology, economics and social science in fisheries research?. Ecology and Society 17 (1): 6.

Holbrook, J.B. (2013). What is interdisciplinary communication? Reflections on the very idea of disciplinary integration, Synthese, 190: 1865-1879.

Horlick-Jones, T. and Sime, J. 2004. Living on the border: knowledge, risk and transdisciplinarity. Futures, Volume 36, Issue 4, May 2004, Pages 441-456.

Huutoniemi, K., Klein, J.T., Bruun, H. and Hukkinen, J. (2010) Analyzing interdisciplinarity: Typology and indicators. Research Policy 39(1): 79-88.

Huutoniemi, K. (2010) Evaluating interdisciplinary research. In: Frodeman, R., Klein, J.T. and Mitcham, K. (eds) Oxford Handbook of Interdisciplinarity. Oxford: Oxford University Press.

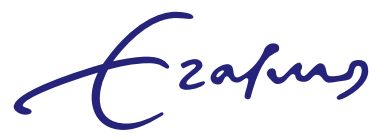


Huzair, F., A.Borda-Rodriguez, M. Upton and J.T. Mugwagwa (2013), An interdisciplinary and development lens on knowledge translation, Science and Public Policy, 40:43-50.

Klein, J.T. 1990. Interdisciplinarity. History, Theory, \& Practice. Wayne State University Press: Detroit.

Klein, J.T. 2008. Evaluation of Interdisciplinary and Transdisciplinary Research. American Journal of Preventive Medicine, Volume 35, Issue 2, Supplement, Pages S116-S123.

Klein, J.T. (2010), The taxonomy of interdisciplinarity. In: Frodeman, R., Klein, J.T., Mitcham, C. (Eds.), Oxford Handbook of Interdisciplinarity, Oxford: Oxford University Press.

Lyall, C., A. Bruce, W. Marsden and L. Meagher (2013), The role of funding agencies in creating interdisciplinary knowledge, Science and Public Policy, 40:62-71.

Marzano, M., Carss, D.M., Bell, S. 2006. Working to Make Interdisciplinarity Work: Investing in Communication and Interpersonal Relationships. Journal of Agricultural Economics, Volume 57, Issue 2, pages 185-197

O'Brien, L., M. Marzano and R.M. White (2013), 'Participatory interdisciplinarity': Towards the integration of disciplinary diversity with stakeholder engagement for new models of knowledge production, Science and Public Policy, 40:51-61.

Podesta, G.P., C.E. Natenzon, C. Hidalgo and F.R.Toranzo (2013), Interdisciplinary production of knowledge with participation of stakeholders: A case study of a collaborative project on climate variability, human decisions and agricultural ecosystems in the Argentine Pampas, Environmental Science and Policy, 26: 40-48.

Reagans, R., and McEvily, B. (2003). Network structure and knowledge transfer: The effects of cohesion and range. Administrative Science Ouarterly, 48(2), pp. 240-267.

Shore, B. and Cross, B.J. 2005. Exploring the role of national culture in the management of large-scale international science projects. International Journal of Project Management, Volume 23, Issue 1, January, Pages 55-64

Petts, J., Owens, S. and Bulkeley, H. 2008. Crossing boundaries: Interdisciplinarity in the context of urban environments. Geoforum, Volume 39, Issue 2, March 2008, Pages 593-601.

Van den Bossche, P., Gijselaers, W.H., Segers, M., \& Kirschner, P.A. (2006). Social and cognitive factors driving teamwork in collaborative learning environments. Small Group Research, 37(2), 490-521.

Wagner, C.S., J.D. Roessner, K. Bobb, J.T. Klein, K.W. Boyack, J. Keyton, I. Rafols and K. Börner (2011), Approaches to understanding and measuring interdisciplinary scientific research (IDR): A review of the literature, Journal of Informetrics, 165:14-26. 